\title{
OsCENH3-GFP 融合转基因水稻的获得及其遗传应用
}

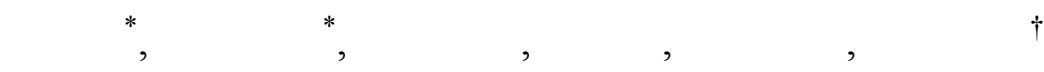

(1) 扬州大学, 江苏省作物遗传生理国家重点实验室, 植物功能基因组学教育部重点实验室, 扬州 225009;

(2) 中国科学院遗传与发育生物学研究所, 北京 100101

* 同等贡献

†联系人, E-mail: zkcheng@genetics.ac.cn

国家自然科学基金(批准号: 30770131, 30530070 和 30671285)及国家高技术研究发展计划(批准号: 2006AA02Z124)资助项目

摘要 通过农杆菌介导的方法, 将水稻组蛋白 H3 与绿色苂光蛋白嵌合基因(OsCENH3-GFP)导入水 稻品种中籼 3037 中, 经 PCR 及 Southern blot 检测, 证明该嵌合基因确已整合到水稻的基因组中. 该 转基因植株发育正常, 有丝分裂及减数分裂行为均正常. 对 $\mathrm{T}_{0}$ 及 $\mathrm{T}_{1}$ 代转基因水稻植株有丝分裂和 减数分裂过程中 GFP 与水稻 CENH3 表达关系的研究结果表明, CENH3 的表达部位与 GFP 的表达 部位完全重叠, 说明 GFP 与水稻 CENH3 已构成融合蛋白, 并且定位于染色体的着丝粒部位. 为探 索该转基因植株在水稻遗传及分子生物学研究中的作用, 利用花粉母细胞减数分裂偶线期染色体, 借助水稻着丝粒串联重复序列 CentO 的 FISH, 发现 GFP 信号与 CentO 信号完全重叠, 证明 CentO 序列确实为水稻不同染色体功能性着丝粒的主要成分. 利用该转基因植株, 分别制作根尖细胞有丝 分裂染色体和花粉母细胞减数分裂染色体制片, 与 anti- $\alpha$-tublin 抗体和 anti-PAIR2 抗体进行苂光免 疫染色反应, 表明该转基因植株携带 GFP 标记的着丝粒, 可以与其他分子生物学手段相结合, 并能 在活体细胞及组织内十分方便地显示每一染色体功能性着丝粒位置, 为深入研究着丝粒的功能提 供了宝贵的遗传材料.

着丝粒是构成真核生物染色体的三大要素之一, 它既是姊妹染色单体的结合点, 又是纺锤丝的附着 点, 因而在染色体配对及维系生物体遗传信息稳定 传递中均起重要作用. 在真核生物中, 着丝粒是 DNA与蛋白质的复合体. 研究表明, 着丝粒的功能 高度保守, 但与着丝粒有关的DNA序列在不同生物 中变化较大. 例如, 发芽酵母的着丝粒由 $125 \mathrm{bp}$ 左右 的特异DNA序列构成 ${ }^{[1]}$. 而其他生物, 包括人类和水 稻, 它们的着丝粒均由特异的高度重复的DNA序列 构成 ${ }^{[2 ~ 11]}$. 在水稻中, 不同的染色体组中着丝粒的 DNA序列也不同. 例如, 栽培稻的着丝粒特异重复 序列CentO由 155 和 $165 \mathrm{bp}$ 两个不同的亚族构成，以 前者为主, 后者是前者插入了 $10 \mathrm{bp}$ 其他序列的结果 [10,11]. 而与着丝粒DNA的快速进化相反, 着丝粒相关 蛋白在真核生物中是非常保守的 ${ }^{[12 ~ 14]}$. 目前已鉴别
了 14 种植物着丝粒蛋白, 其中包括与着丝粒DNA特 异结合的组蛋白 H3 (centromere-specific histone H3, CENH3)和CENP-C (centromere protein C) ${ }^{[15 \sim 18]}$. 并且 CENP-C的定位依赖于CENH3 的存在, 反之则不然 [19]. 也就是说, CENH3 在真核生物着丝粒的建立和 功能实现中起着关键作用, 它决定着丝粒组装的位 置, 并在着丝粒DNA与组蛋白之间形成特定的连接 结构 $[12214]$. 如果没有它的结合, 染色体就不能进行正 常的分离与传递. 在果蝇和小鼠中已证明, 当 $\mathrm{CENH3}$ 被破坏时, 所有被检测的着丝粒蛋白都被错 误定位 ${ }^{[20,21]}$. 在活性着丝粒中, $\mathrm{CENH} 3$ 取代了核小体 组蛋白八聚体中的组蛋白 H3, 形成含 CENH3 的核小 体 ${ }^{[22]}$. 因此, $\mathrm{CENH} 3$ 是真核生物功能着丝粒的根本 特征, 是功能着丝粒的共同基础, 可作为功能着丝粒 染色质的识别标记. 
绿色苂光蛋白 (green fluorescent protein, GFP)是 一类存在于水母、水螅和珊瑚等腔肠动物体内的一种 功能独特的生物发光蛋白. 当受到紫外或蓝光激发 时, GFP发射绿色菼光. 它是一种操作方便, 不用加 外源底物, 就能在活细胞中检测的分子探针. 在水稻 中, OsCENH3 基因已通过同源序列比较的方法得以 鉴定和克隆 ${ }^{[23]}$. 本研究将OsCENH3 基因与 GFP 基因 构建成嵌合基因，通过农杆菌介导法将其导入水稻 中, 利用GFP的表达部位来反映水稻CENH3 的染色 体定位, 并试图与目前细胞学研究较流行的染色体 苂光原位杂交, 以及蛋白质抗体苂光免疫染色反应 等手段相结合, 研究水稻OsCENH3-GFP嵌合转基因 植株在遗传及分子生物学研究中的潜在作用.

\section{1 材料与方法}

( i ) 植物材料. 水稻(Oryza sativa L.)受体品种 为籼稻品种中籼 3037 .

（ii）农杆菌菌株及质粒. 携带有GFP基因的质 粒eGFP由Yasuo Niwa博士(Shizuoka University, Japan) 赠送, 其中的 $G F P$ 基因分别由CaMV $35 \mathrm{~S}$ 启动子、烟 草花叶病毒(TMV) $\Omega$ 增强子序列及NOS终止子控制 [24].

根据水稻 OsCENH3 基因的 cDNA(AK101975)序 列设计 PCR 引物, 并分别在 PCR 产物的 5'木端和 3' 末端引入酶切位点. 设计的引物序列为 CEFPF (5'-CGTCGACGCCGAGATGGCTCGC-3'，下画线部分 为 Sal I 的酶切位点)和 CEFPR (5'-CCCATGGCCCAAGGCCTCCGCCCACC-3'，下画线部分为 $N C O$ I的 酶切位点). 以水稻 $\mathrm{CDNA}$ 为模板进行 PCR 扩增, PCR 产物连入 pGEM-T 载体后经 Sal I 和 Nco I 双酶切将 PCR 产物克隆入 eGFP 载体的 CaMV 35S 启动子后的 $\Omega$ 增强子和 GFP 基因之间, 构建成 35S-OsCENH3GFP-NOS 嵌合基因, 然后通过 EcoR I 和 Hind III 双酶 切将 35S-OsCENH3-GFP-NOS 嵌合基因克隆到双元载 体 pCAMBIA1300 的多克隆位点中形成含 OsCENH3-

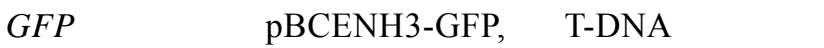
见图 1. 双元载体pBCENH3-GFP经冻融法 ${ }^{[25]}$ 导入根 癌农杆菌(Agrobacterium tumefaciens)菌株EHA105 感 受态细胞中.

(iii) 农杆菌介导的水稻转化. 以籼稻品种中籼 3037 的成熟胚诱导愈伤组织, 并用于随后的转化. 水 稻愈伤组织的诱导培养及其与农杆菌的共培养、抗性 愈伤组织的篮选及其再生等参照文献[26]的方法进 行.

(iv) 转基因水稻植株总 DNA 的 PCR 分析. 潮 霉素抗性基因 DNA 片段的 PCR 扩增引物为 HP1 (5'-GCTGTTATGCGGCCATTGTC-3')与 HP2 (5'-GACGTCTGTCGAGAAGTTTC-3'), 可从潮霉素抗性基 因编码区扩增出 $614 \mathrm{bp}$ 的 DNA 片段. 反应条件为: $94^{\circ} \mathrm{C}, 3 \mathrm{~min} ; 94^{\circ} \mathrm{C}, 50 \mathrm{~s} ; 55^{\circ} \mathrm{C}, 50 \mathrm{~s} ; 72^{\circ} \mathrm{C}, 50 \mathrm{~s}, 30$ 个循 环; $72^{\circ} \mathrm{C}, 10 \mathrm{~min}$.

（v）转基因水稻植株总DNA的Southern blot分 析. 水稻植株叶片总DNA的提取参考Murray等人 [27] 的方法. Southern杂交分析时, 取 $10 \mu \mathrm{g}$ 水稻叶片总 DNA 经限制性内切酶消化, $0.8 \%$ 凝胶电泳分离; 用毛 细管法将 DNA 转移至尼龙膜上, 以地高辛 (Digoxigenin, Roche)标记的HPT基因编码区序列作 为探针进行杂交, 具体方法按Sambrook ${ }^{[28]}$ 和Roche公 司推荐的操作程序进行.

(vi) 苂光原位杂交(fluorescence in situ hybridization, FISH). 苂光原位杂交按Zhang等人 ${ }^{[29]}$ 的方法 进行. 为确定染色体上着丝粒的位置, 以含有水稻着 丝粒特异串联重复序列CentO的克隆pRCS2 作探针, 以Digoxigenin-11-dUTP标记后与玻片上染色体杂交, 再以Digoxigenin抗体偶联的anti-digoxigenin- rhodamine进行检测，染色体以DAPI染色. 显微观察在 Olympus BX61 苂光显微镜下进行，在不同波长的滤 色片下, 分别观察目标染色体及其杂交信号, 用 DVC1412 CCD相机及IPLab软件进行图像拍摄, 并利 用Adobe Photoshop CS2 软件进行图像处理.

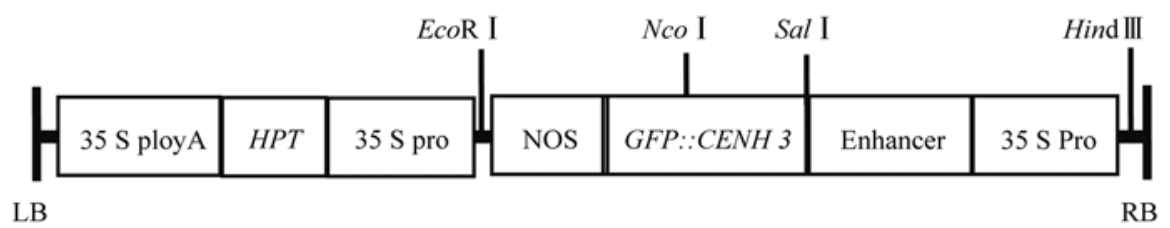

图 1 含 OsCENH3-GFP 嵌合基因载体 pBCENH3-GFP 的 T-DNA 区结构

$35 \mathrm{~S}$ pro, CaMV 35S 基因启动子; 35S polyA, CaMV 35S 基因终止子; NOS, 胭脂碱合成酶基因的终止子; HPT, 潮霉素抗性基 因; Enhancer, 烟草花叶病毒(TMV) $\Omega$ 增强子序列; LB 和 RB, T-DNA 区的左边界和右边界 
（vii）蛋白质抗体免疫苂光染色反应. 采集新鲜 根尖及处于减数分裂期的幼穗, 用 $4 \%$ 多聚甲醛(质量 体积比)室温固定后, 选取细胞分裂时期合适的试样, 置于载玻片上, 滴加一滴 $1 \times \mathrm{PBS}$, 将试样捣碎加盖盖 玻片并压片. 压好的玻片于 $-20^{\circ} \mathrm{C}$ 放置 $30 \mathrm{~min}$ 后液氮 浸泡 $15 \mathrm{~min}$ ，用刀片迅速揭去盖玻片，70\%，90\%， $100 \%$ 酒精依次梯度脱水后自然晾干. 每张载玻片上 滴加 $20 \mu \mathrm{L}$ 含有抗-CENH3, 抗- $\alpha$-微管蛋白(tublin)或 抗-PAIR2 等不同抗体的 $1 \times \mathrm{TNB}$ 溶液(含 $0.1 \mathrm{~mol} / \mathrm{L}$ Tris-HCl, pH 7.5, $0.15 \mathrm{~mol} / \mathrm{L} \mathrm{NaCl}, 0.5 \%$ 封阻剂 (blocking reagent), 盖上盖玻片, 于 $37^{\circ} \mathrm{C}$ 湿盒中保温 过夜. 以 $1 \times \mathrm{PBS}$ 洗片 3 次, 然后滴加 $50 \mu \mathrm{L}$ 含有 TexRed-抗兔抗体的 $1 \times \mathrm{TNB}$ 溶液, 于 $37^{\circ} \mathrm{C}$ 避光保温 $30 \mathrm{~min}$; 再以 $1 \times \mathrm{PBS}$ 洗片 3 次后晾干, 加 $20 \mu \mathrm{L}$ 含有 DAPI 的抗裉色剂, 盖上盖玻片, 在苂光显微镜下观 察拍照.

\section{2 结果与分析}

\section{1 转基因水稻植株的获得}

以籼稻品种中籼 3037 的成熟胚为起始培养材料, 诱导初生愈伤组织, 并用农杆菌 EHA105/pBCENH3GFP 侵染, 侵染后的愈伤组织在共培养培养基上培 养 $3 \mathrm{~d}$ 后移至含潮霉素的篮选培养基中进行篮选培养, 经过 3 代约 6 周的选择培养, 即可获得生长良好的抗 性愈伤组织, 将其转至分化培养基上分化成苗. 通过 上述水稻转化程序最终获得 16 株转基因植株.

为检测外源基因是否整合于水稻的基因组上, 先对获得的转化植株进行 PCR 分析. 从所获得的 16 株转基因水稻植株叶片分别提取总 DNA, 用于 PCR 分析. 结果在其中的 5 株植株总 DNA 中特异地扩增 出 $H P T$ 基因片段(图 2 中的 5,6,8,12,18), 与阳性对 照(以 pBCENH3-GFP 质粒 DNA 为模板)相同(图 2 中
的 3), 而在未转化植株总 DNA 中没有扩增出相应的 片段(图 2 中的 4).

选取以上经 PCR 鉴定为含有 $H P T$ 基因的转基因 植株, 用 Hind III 酶切其总 DNA, 并进行 Southern blot 分析, 结果见图 3. 由图 3 可知, 在 PCR 检测为 $H P T$ 基因阳性的转基因水稻植株中, 均有特异的杂交条 带出现(图 3 中的 3 7), 而在未转化对照植株中未发 现有杂交信号(图 3 中的 2), 说明 HPT 基因确已整合 进了转基因水稻植株的基因组. 因在 HPT 基因的编 码区没有 Hind III 酶切位点, 所以杂交条带的数目可 用于估计外源基因的插入拷贝数及其整合位点. 从 图 3 可以看出, 不同转基因水稻植株的杂交条带的大 小有所不同, 显示外源基因在转基因水稻的基因组 中的整合位点是不同的; 另外，不同转基因水稻植株 中都只有 1 条杂交条带, 据此推测转基因水稻植株中 可能只含有 1 个外源基因整合位点.

\section{2 转基因水稻的形态及细胞分裂行为观察}

为了确定转 OsCENH3-GFP 基因植株有没有出 现正常生理功能的改变, 我们从秧苗期至成熟期对 该转基因植株进行了详细的形态观察, 发现它们与 未转化对照之间没有明显的性状改变, 在株叶形态、 穗粒形态、株高及抽穗期等方面均与未转化的中籼 3037 完全相同, 结实率正常. 同时对转基因植株的有 丝分裂及减数分裂过程进行了详细研究, 结果表明, 它们的根尖细胞可以进行正常的有丝分裂, 染色体 分离正常. 当用水稻着丝粒特异串联重复序列 CentO 进行 FISH 杂交时, 发现 CentO 可正常地杂交到每一 染色体的着丝粒处(图 4(a)), 表明 OsCENH3-GFP 基 因的导入并没有影响 CentO 序列在每一染色体着丝 粒处的有效复制. 花粉母细胞减数分裂观察表明, 细 线期染色体形态正常 (图 4(b)), 粗线期同源染色体联

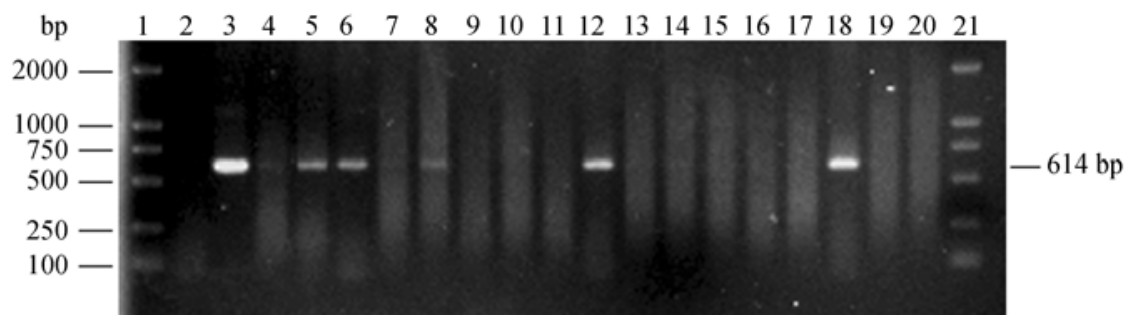

图 2 转基因水稻植株总 DNA 的 PCR 分析

1 和 21 , DNA 分子量标记; 2 , 水; 3 , 质粒 DNA; 4 , 未转化的对照植株; 520 , 不同转基因植株 


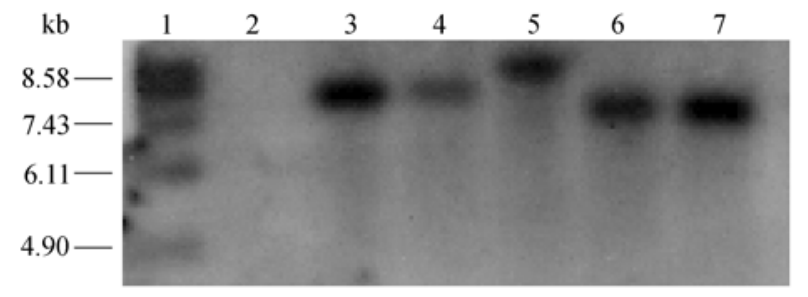

图 3 转基因水稻植株总 DNA 的 Southern 杂交分析 用 Hind III 酶切基因组 DNA 并用地高辛标记 HPT 编码序列的 Southern blot 分析. 1, DNA 分子量标记; 2, 未转化对照植株; 3 7, 5 个不同的 HPT 基因 PCR 阳性转基因植株

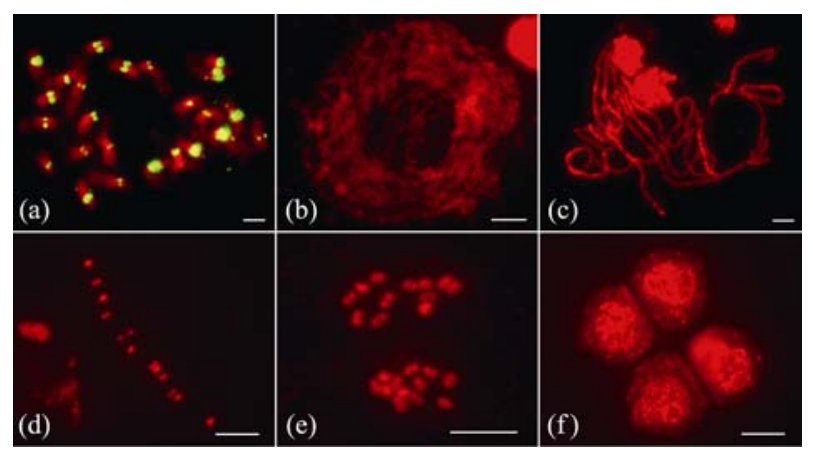

图 4 转基因水稻植株的有丝分裂及减数分裂观察

(a) 根尖有丝分裂中期染色体用着丝粒特异重复序列 CentO 的苂 光原位杂交结果; (b) 减数分裂细线期染色体; (c) 减数分裂粗线 期染色体; (d) 减数分裂中期 I 染色体; (e) 减数分裂后期 I 染色体;

(f) 减数分裂四分体. 染色体以 DAPI 染色. 标尺示 $5 \mu \mathrm{m}$

会成 12 个二价体(图 4(c)), 中期 I 的 12 个二价体能 够规则地排列在赤道板上(图 4(d)), 后期 I 同源染色 体分离正常(图 4(e)), 并形成正常的二分体. 减数第 二次分裂亦完全正常，最终形成正常的四分体(图 4(f)). 由此可见, 该转基因植株的形态发育正常, 并 且有丝分裂及减数分裂过程均未出现异常变化, 可 作为遗传材料用于水稻着丝粒功能的相关研究中.

\section{$2.3 \mathrm{GFP}$ 与 OsCENH3 在转基因水稻中的细胞学} 定位

为研究转基因水稻中 GFP 与 $\mathrm{OsCENH3}$ 蛋白的 表达情况, 我们取转基因植株的根尖及减数分裂期 幼穗，经 4\%的多聚甲醛短暂固定后，分别制作根尖 细胞有丝分裂涂片和花粉母细胞减数分裂涂片, 冰 冻揭除盖玻片后，以抗-CENH3 抗体进行免疫反应, 并进行后续的二级抗体偶联检测反应, 结果见图 5. 在细胞有丝分裂的间期, 在显微镜的绿色通道中每 个细胞中可以观察到 24 个绿色苂光信号点(图 5(a)),
而红色通道同一个细胞也可见 24 个 OsCENH3 苂光 免疫染色的红色信号点(图 5(b)). 并且 GFP 绿色苂光 信号与 OsCENH3 的红色信号完全重叠, 且均位于细 胞核内的染色体上(图 5(c)). 在有丝分裂中期细胞中, GFP 的绿色苂光信号点和 OsCENH3 苂光免疫染色的 信号(图 5(d)和(e))也均位于染色体上, 它们的共定位 结果表明, GFP 绿色菼光信号与 OsCENH3 信号重叠 于每一染色体的着丝粒部位(图 5(f)). 在花粉母细胞 减数分裂的偶线期早期, 可以看到数目不等的绿色 菼光信号点(图 5(g)), 同一个细胞中的 OsCENH3 红 色苂光信号也有同样的趋势 (图 5(h)), 并且绿色苂光 信号与 OsCENH3 信号重叠于细胞核内的染色体上 (图 5(i)). 到了减数分裂粗线期, 24 条染色体配对联 会成 12 个二价体, 所以我们从每个花粉母细胞中可 以观察到 12 个 GFP 绿色菼光信号点和 12 个 OsCENH3 的红色苂光信号点(图 5(j)和(k)), 而且 GFP 信号与 OsCENH3 信号重叠于染色体上(图 5(1)). 到了 减数分裂的终变期, 每一二价体由于同源染色体内 非姊妹染色单体的相互排斥, 部分区域已经分开, 但 同源染色体由于交叉而仍然联系在一起, 因此, 在这 个时期每个二价体上可以观察到有两个 GFP 绿色苂 光信号点和两个 OsCENH3 苂光免疫染色的红色信号 点(图 5(m)和(n)), 并且绿色苂光信号点和 OsCENH3 红色信号点也重叠于染色体上(图 5(o)). 以上结果说 明, 在转 OsCENH3-GFP 嵌合基因的水稻植株中, GFP 蛋白与 OsCENH3 已构成融合蛋白, 在细胞分裂 过程中两者均定位于染色体的着丝粒部位, 可以用 OsCENH3-GFP 融合蛋白的表达部位来反映水稻 $\mathrm{CENH3}$ 的表达部位.

\subsection{OsCENH3-GFP 融合蛋白与水稻着丝粒特异重} 复序列 CentO 的细胞学定位

为探索该转基因植株在水稻遗传及分子生物学 研究中的作用, 将该转基因材料与染色体苂光原位 杂交及蛋白质抗体苂光免疫染色反应等手段相结合, 研究水稻 OsCENH3-GFP 融合转基因植株在遗传及 分子生物学研究中的潜在作用. 首先, 利用花粉母细 胞减数分裂偶线期染色体进行水稻着丝粒串联重复 序列 CentO 的 FISH 杂交, 以验证 CentO 在水稻染色 体上的位置. 由于 GFP 绿色荧光在 FISH 杂交的染色 体变性过程中容易消失, 因此在进行 FISH 杂交之前 先对细胞染色体的图像及 GFP 信号进行拍摄, 在记 录每一细胞在玻片上的坐标后, 再进行后续的 FISH 
杂交，并进行杂交信号的检测与拍摄，拍摄的杂交信 号根据所在的染色体位置利用 Photoshop 软件进行图
像叠加. 图 6(a)为一处于减数分裂偶线期的花粉母细 胞绿色苂光信号的表达情况，每个细胞可见明显的

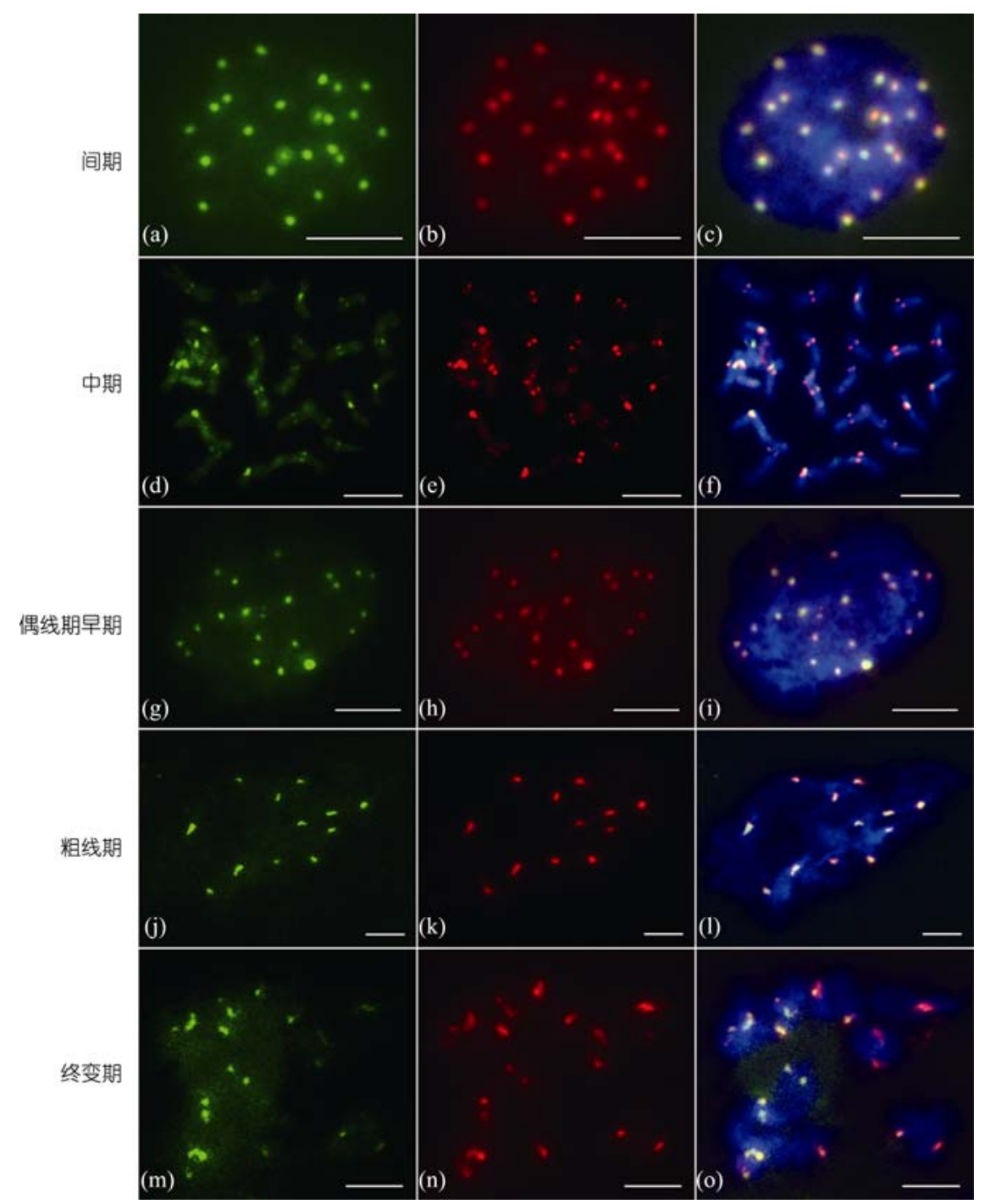

图 5 OsCENH3-GFP 融合蛋白在转基因水稻中的定位

(a), (d), (g), (j), (m) 分别为细胞分裂不同时期 GFP 信号; (b), (e), (h), (k), (n) 分别为细胞分裂不同时期 CENH3 蛋白苂光免疫 染色的信号; (c), (f), (i), (1), (o)分别为细胞分裂不同时期 GFP 信号与 CENH3 蛋白苂光免疫染色信号的共定位, 染色体用 DAPI 染色. 标尺示 $5 \mu \mathrm{m}$

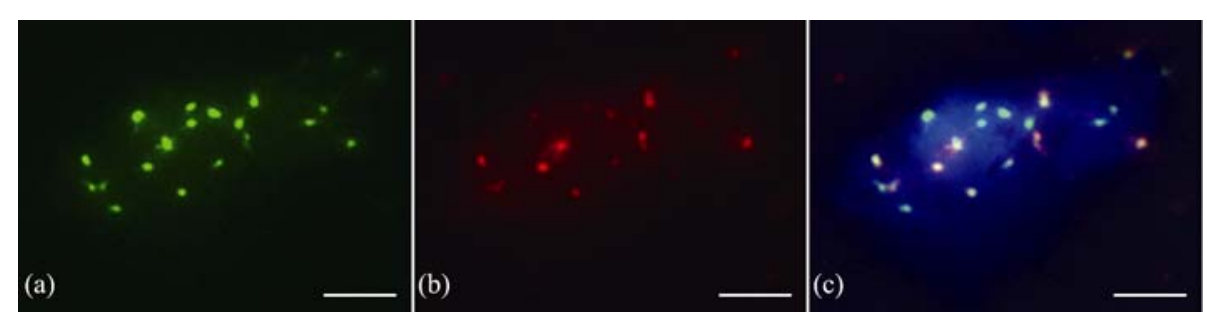

图 6 OsCENH3-GFP 融合蛋白与水稻着丝粒特异重复序列 CentO 在转基因水稻中的定位

(a) 减数分裂偶线期 OsCENH3-GFP 融合蛋白的信号; (b)水稻着丝粒特异重复序列 CentO 苂光原位杂交结果; (c) OsCENH3-GFP 融合蛋白的信号与水稻着丝粒特异重复序列 CentO 菼光原位杂交信号的共定位, 染色体用 DAPI 染色. 标尺示 $5 \mu \mathrm{m}$ 
GFP 绿色信号点, 图 6(b)为水稻着丝粒特异重复序列 序列 CentO 的苂光原位杂交结果, 每个细胞中同样可 以观察到 CentO 的红色信号点, 从 OsCENH3-GFP 融 合蛋白和水稻着丝粒特异重复序列 CentO 的共定位 结果可以看出, GFP 的信号(绿色)与 CentO 的荧光原 位杂交信号(红色)重叠于染色体上(图 6(c)). 由于 $\mathrm{CENH} 3$ 是功能性着丝粒的识别标志, 从而证明了 CentO 序列确实为水稻不同染色体功能性着丝粒的 主要成分.

\subsection{OsCENH3-GFP融合蛋白与微管蛋白和PAIR2} 蛋白的细胞学定位

蛋白的细胞与亚细胞定位是研究蛋白质相互作 用的重要手段之一. 为探索该转基因植株中 GFP 信 号在水稻分子生物学研究中的潜在价值, 我们选取 两个在细胞分裂过程中具有重要功能的蛋白, 利用 它们的抗体进行免疫苂光染色反应, 并观察其与 GFP 信号的相对位置. 其中微管蛋白与细胞分裂过程中 纺锤体的形成密切相关, 在细胞有丝分裂和减数分
裂过程中均发挥重要作用. 利用根尖细胞制作有丝 分裂染色体涂片, 并与抗- $\alpha$-微管蛋白抗体进行免疫 苂光染色反应. 在细胞有丝分裂的间期, 每个细胞有 明显的 OsCENH3-GFP 融合蛋白信号点(图 7(a)), 且 均位于细胞核内; 同一细胞的 $\alpha$-微管蛋白苂光免疫 染色的红色信号显示, 微管蛋白主要分布于细胞质 中(图 7(b)); 从 OsCENH3-GFP 融合蛋白和 $\alpha$-微管蛋 白的共定位结果可以看出, GFP 信号位于细胞核内的 染色体上, 而微管蛋白主要分布于核外的细胞质中 (图 7(c)); 到了有丝分裂中期, 染色体着丝粒排列于 赤道板上, 染色体位于细胞的中部, OsCENH3-GFP 融合蛋白的信号也随之集中于细胞中部的染色体上 (图 7(d)和(f)), 而 $\alpha$-微管蛋白(纺锤丝)分布于染色体的 两侧(图 7(e)和(f)), 并有 $\alpha$-微管蛋白与 OsCENH3-GFP 融合蛋白的信号紧密相连(图 7(f)), 从而证明在细胞 分裂的中期, 微管蛋白重新组装成了纺锤体, 并牵引 每一染色体的着丝粒以使染色体向细胞两极移动.

同源染色体的配对是减数分裂偶线期染色体的

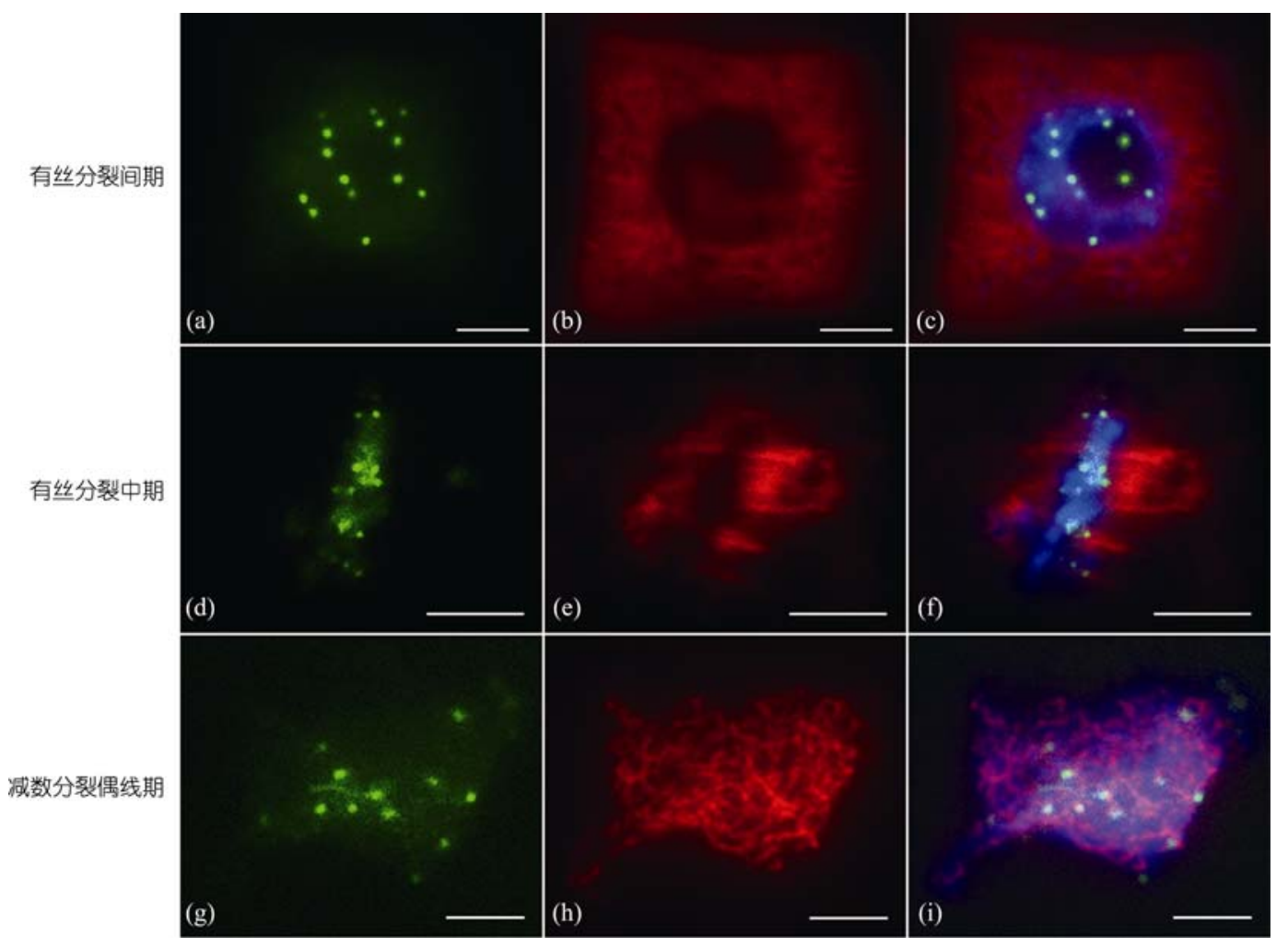

图 7 OsCENH3-GFP 融合蛋白与微管蛋白和 PAIR2 蛋白在转基因水稻中的定位

(a), (d), (g)分别为细胞分裂不同时期 OsCENH3-GFP 融合蛋白的信号; (b)和(e)分别为有丝分裂间期(b)和中期(e) $\alpha$-微管蛋白 荧光免疫染色的结果; (c)和(f)分别为有丝分裂间期 (c) 和中期 (f) OsCENH3-GFP 融合蛋白与 $\alpha$-微管蛋白的共定位, 染色体用 DAPI 染色; (h) 减数分裂偶线期 PAIR2 蛋白荧光免疫染色的结果; (i) 减数分裂偶线期 PAIR2 蛋白与 OsCENH3-GFP 融合蛋 白在细胞中的共定位, 染色体用 DAPI 染色. 标尺示 $5 \mu \mathrm{m}$ 
重要特征, 在减数分裂过程中必须有一系列重要蛋 白参与同源染色体的联会和交换, 其中PAIR $2^{[30]}$ 是参 与同源染色体联会过程中染色体轴心形成的特殊蛋 白, 该蛋白的功能异常将导致同源染色体不能发生 联会. 本研究用该蛋白的抗体进行转基因植株花粉 母细胞减数分裂期染色体免疫苂光染色反应，结果 在偶线期可见明显的OsCENH3-GFP融合蛋白信号点 (绿色), 它们均位于染色体上(图 7(g)和(i)), 同一细胞 PAIR2 蛋白苂光免疫染色红色信号显示(图 7(h)和(i)), PAIR2 蛋白位于每一染色体的轴心, 证明了 PAIR2 蛋 白确实是减数分裂过程中与染色体配对有关的蛋白, 而绿色的苂光信号点正位于这些染色体上. 以上结 果进一步明确了OSCENH3-GFP融合蛋白定位于染色 体的着丝粒部位, 证明该转基因植株携带GFP标记的 着丝粒, 能够广泛与其他分子生物学手段相结合, 并 能在活体细胞及组织内十分方便地显示每一染色体 功能性着丝粒位置.

\section{3 讨论}

GFP 基因是能在细胞内表达，且不需要其他外 源底物参与的全新报告基因, 是目前分子生物学家 和细胞生物学家用于目的蛋白示踪和定量的最有用 的研究工具. 较以往常用的报告基因, 如 GUS 等相 比较, GUS 等基因编码的是酶蛋白, 检测需要底物或 辅助因子的参与, 有些还对细胞具有一定的损伤, 因
而GFP作为一种基因表达的标记物优于这些传统的 报告基因, GFP作为一种极具潜力的标记物为研究基 因功能及表达调控提供了极大的便利. 在拟南芥中 已经有利用 CENH3-GFP 基因来研究CENH3 蛋白在 细胞分裂过程中表达特性的报道 ${ }^{[31]}$, 而在作为分子 生物学研究的禾本科作物模式生物水稻中, 还没有 有关的报道. 本研究就是将控制水稻中 CENH3 合成 的基因(OsCENH3)与绿色苂光蛋白基因 $G F P$ 构建成 OsCENH3-GFP嵌合基因, 通过农杆菌介导导入水稻 品种中籼 3037 中, 使得每一有功能的着丝粒均能高 效结合OsCENH3-GFP融合蛋白, 从而使水稻着丝粒 的研究从传统光学显微镜下的主缢痕, 过度到借助 相关DNA序列标记的着丝粒, 最终过度到能够直接 显示着丝粒特异组蛋白的功能性着丝粒上来. 并且 本研究结果表明, CENH3 的表达部位与GFP蛋白的 表达部位一致, 可以通过检测GFP蛋白来间接检测 $\mathrm{CENH} 3$ 的表达部位，这大大简化了功能性着丝粒检 测的流程. 本研究结果还表明, OsCENH3-GFP嵌合 基因转基因水稻可以方便地与染色体苂光原位杂交 和蛋白质抗体苂光免疫染色反应等分子生物学手段 结合, 研究水稻着丝粒组蛋白 $\mathrm{CENH} 3$ 与染色体分裂 行为的关系以及与功能性着丝粒DNA序列和其他蛋 白质之间的关系.

\section{参考文献}

1 Cheeseman I M, Drubin D G, Barnes G. Simple centromere, complex kinetochore: Linking spindle microtubules and centromeric DNA in budding yeast. J Cell Biol, 2002, 157: 199-203 [DOI]

2 Schueler M G, Higgins A W, Rudd M K, et al. Genomic and genetic definition of a functional human centromere. Science, 2001, 294: $109-115 \underline{\text { [DOI] }}$

3 Rudd M K, Schueler M G, Willard H F. Sequence organization and functional annotation of human centromeres. Cold Spring Harb Symp Quant Biol, 2003, 68: 141-149 $\underline{\text { [DOI] }}$

4 Wevrick R, Willard H F. Long-range organization of tandem arrays of $\alpha$ satellite DNA at the centromeres of human chromosomes: High frequency array-length polymorphism and meiotic stability. Proc Natl Acad Sci USA, 1989, 86: 9394-9398 [DOI]

5 Neumann P, Yan H, Jiang J. The centromeric retrotransposons of rice are transcribed and differentially processed by RNA interference. Genetics, 2007, 176: 749—761 $\underline{\text { DOI] }}$

$6 \mathrm{Ma}$ J, Jackson S A. Retrotransposon accumulation and satellite amplification mediated by segmental duplication facilitate centromere expansion in rice. Genome Res, 2006, 16: 251-259 $\underline{\text { [DOI] }}$

7 Yan H H, Ito H, Nobuta Kan H, et al. Genomic and genetic characterization of rice Cen3 reveals extensive transcription and evolutionary implications of a complex centromere. Plant Cell, 2006, 18: 2123-2133[DOI]

8 Zhang W L, Yi C D, Bao W D, et al. The transcribed 165-bp CentO satellite is the major functional centromeric element in the wild rice species Oryza punctata. Plant Physiol, 2005, 139: 306-315 $\underline{\text { [DOI] }}$

9 Nagaki K, Neumann P, Zhang D, et al. Structure, divergence, and distribution of the CRR centromeric retrotransposon family in rice. Mol Biol Evol, 2005, 22: 845-855[DOI] 
10 Cheng Z K, Dong F G, Langdon T, et al. Functional rice centromeres are marked by a satellite repeat and a centromere-specific retrotransposon. Plant Cell, 2002, 14: 1691-1704 [DOI]

11 Dong F G, Miller J T, Jackson S A, et al. Rice (Oryza sativa) centromeric regions consist of complex DNA. Proc Natl Acad Sci USA, 1998, 95: 8135-8140 [DOI]

12 Amor D J, Kalitsis P, Sumer H, et al. Building the centromere: From foundation proteins to 3D organization. Trends Cell Biol, 2004, 14: $359-368$ [DOI]

13 Sullivan B A, Blower M D, Karpen G H. Determining centromere identity: Cyclical stories and forking paths. Nat Rev Genet, 2001, 2: $584-596 \underline{\text { DOI] }}$

14 Henikoff S, Ahmad K, Malik H S. The centromere paradox: Stable inheritance with rapidly evolving DNA. Science, 2001, 293: 1098$1102 \underline{\text { [DOI] }}$

15 Zhong C X, Marshall J B, Topp C, et al. Centromeric retroelements and satellites interact with maize kinetochore protein CENH3. Plant Cell, 2002, 14: 2825-2836 [DOI]

16 Talbert P B, Masuelli R, Tyagi A P, et al. Centromeric localization and adaptive evolution of an Arabidopsis histone H3 variant. Plant Cell, 2002, 14: 1053-1066 [DOI]

17 Yu H G, Hiatt E N, Dawe R K. The plant kinetochore. Trends Plant Sci, 2000, 5: 543-547 [DOI]

18 Hoopen R T, Schleker T, Manteuffel R, et al. Transient CENP-E-like kinetochore proteins in plants. Chromosome Res, 2002, 10: 561$570 \underline{[\mathrm{DOI}]}$

19 Westermann S, Cheeseman I M, Anderson S, et al. Architecture of the budding yeast kinetochore reveals a conserved molecular core. J Cell Biol, 2003, 163: 215-222 [DOI]

20 Blower M D, Karpen G H. The role of Drosophila CID in kinetochore formation, cell-cycle progression and heterochromatin interactions. Nat Cell Biol, 2001, 3: 730-739 [DOI]

21 Howman E V, Fowler K J, Newson A J, et al. Early disruption of centromeric chromatin organization in centromere protein A (Cenpa) null mice. Proc Natl Acad Sci USA, 2000, 97: 1148-1153 [DOD]

22 Yoda K, Ando S, Morishita S, et al. Human centromere protein A (CENP-A) can replace histone H3 in nucleosome reconstitution in vitro. Proc Natl Acad Sci USA, 2000, 97: 7266-7271 [DOI]

23 Nagaki K, Cheng Z K, Ouyang S, et al. Sequencing of a rice centromere uncovers active genes. Nat Genet, 2004, 36: 138-145[DOI]

24 Niwa Y, Hirano T, Yoshimoto K, et al. Non-invasive quantitative detection and applications of non-toxic, S65T-type green fluores-

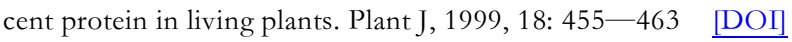

25 Hofgen R, Willmitzer L. Storage of competent cells for Agtobacterium transformation. Nucleic Acids Res, 1988, 16: 9877[DOI]

26 于恒秀, 刘巧泉, 王玲, 等. 根癌农杆菌介导的水稻成熟胚转化系统的优化及转 metr 基因植株的获得. 遗传, 2005, 27: 756一 762

27 Murray M G, Thompson W F. Rapid isolation of high molecular weight plant DNA. Nucleic Acid Res, 1980, 8: 4321-4325[DOI]

28 Sambrook J, Fritsch E F, Maniatis T. Molecular Cloning: A Laboratory Manual. 2nd ed. Cold Spring Harbor: Cold Spring Harbor Laboratory Press, 1989

29 Zhang D, Yang Q, Bao W, et al. Molecular cytogenetic characterization of the Antirthinum majus genome. Genetics, 2005, 169: 325$335 \underline{[D O I]}$

30 Nonomura K, Nakano M, Eiguchi M, et al. PAIR2 is essential for homologous chromosome synapsis in rice meiosis I. J Cell Sci, 2006, 119: $217-225 \underline{[\mathrm{DOI}]}$

31 Lermontova I, Schubert V, Fuchs J, et al. Loading of Arabidopsis centromeric histone CENH3 occurs mainly during G2 and requires the presence of the histone fold domain. Plant Cell, 2006, 18: 2443-2451 [DOD] 